\title{
BMJ Open Association of common mental disorder symptoms with health and healthcare factors among women in rural western India: results of a cross-sectional survey
}

\author{
Apurv Soni, ${ }^{1}$ Nisha Fahey, ${ }^{1,2}$ Nancy Byatt, ${ }^{1}$ Anusha Prabhakaran, ${ }^{3}$ \\ Tiffany A Moore Simas, ${ }^{1}$ Jagdish Vankar, ${ }^{3}$ Ajay Phatak, ${ }^{3}$ Eileen O'Keefe, ${ }^{4}$ \\ Jeroan Allison, ${ }^{1}$ Somashekhar Nimbalkar ${ }^{3}$
}

To cite: Soni A, Fahey N, Byatt N, et al. Association of common mental disorder symptoms with health and healthcare factors among women in rural western India: results of a cross-sectional survey. BMJ Open 2016;6: e010834. doi:10.1136/ bmjopen-2015-010834

- Prepublication history and additional material is available. To view please visit the journal (http://dx.doi.org/ 10.1136/bmjopen-2015010834)

Received 14 December 2015 Accepted 7 June 2016

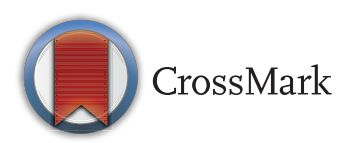

\footnotetext{
${ }^{1}$ University of Massachusetts Medical School, Worcester, Massachusetts, USA ${ }^{2}$ Des Moines University, Des Moines, lowa, USA ${ }^{3}$ Pramukhswami Medical College, Karamsad, Gujarat, India

${ }^{4}$ Boston University, Boston, Massachusetts, USA
}

Correspondence to Apurv Soni;

Apurv.Soni@umassmed.edu

\section{ABSTRACT}

Objectives: Information about common mental disorders (CMD) is needed to guide policy and clinical interventions in low-income and middle-income countries. This study's purpose was to characterise the association of CMD symptoms with 3 inter-related health and healthcare factors among women from rural western India based on a representative, crosssectional survey.

Setting: Surveys were conducted in the waiting area of various outpatient clinics at a tertiary care hospital and in 16 rural villages in the Anand district of Gujarat, India.

Participants: 700 Gujarati-speaking women between the ages of 18-45 years who resided in the Anand district of Gujarat, India, were recruited in a quasirandomised manner.

Primary and secondary outcomes measures: CMD symptoms, ascertained using WHO's SelfReporting Questionnaire-20 (SRQ-20), were associated with self-reported (1) number of healthcare visits in the prior year; (2) health status and (3) portion of yearly income expended on healthcare.

Results: Data from 658 participants were used in this analysis; 19 surveys were excluded due to incompleteness, 18 surveys were excluded because the participants were visiting hospitalised patients and 5 surveys were classified as outliers. Overall, 155 (22.8\%) participants screened positive for CMD symptoms (SRQ-20 score $\geq 8$ ) with most $(81.9 \%)$ not previously diagnosed despite contact with healthcare provider in the prior year. On adjusted analyses, screening positive for CMD symptoms was associated with worse category in self-reported health status (cumulative OR=9.39; 95\% Cl 5.97 to 14.76), higher portion of household income expended on healthcare (cumulative OR=2.31; 95\% CL 1.52 to 3.52 ) and increased healthcare visits in the prior year (incidence rate ratio $=1.24 ; 95 \% \mathrm{Cl} 1.07$ to 1.44 ).

Conclusions: The high prevalence of potential CMD among women in rural India that is unrecognised and associated with adverse health and financial indicators highlights the individual and public health burden of CMD.

\section{Strengths and limitations of this study}

- Our novel data set contains information about health status and healthcare usage of reproductive-aged women in rural India, an underserved and understudied population.

- This is the first study to report the association of screening positive for symptoms of common mental disorders (CMD) with self-reported health status, healthcare expenditure and healthcare usage among women in rural India.

- The multivariable negative binomial and ordinal logistic regression allowed robust estimation of disease-adjusted association, which preserved the data structure of self-reported measures.

- We are limited by our cross-sectional study design that limits causal interpretation. However, identification of the associations between women screening positive for CMD symptoms and healthcare expenditure holds significance in the context of a system where the majority of healthcare costs are out of pocket and women face barriers in accessing healthcare.

\section{INTRODUCTION}

Depression is the leading cause of total years lived with disability globally. ${ }^{12}$ In developed countries, depression has been associated with lower health status and productivity, increased ambulatory and emergency hospital visits, and greater healthcare costs. ${ }^{3}{ }^{4}$ Despite recent estimates suggesting that lowincome and middle-income countries (LMIC) experience over $80 \%$ of the worldwide burden attributed to depression, ${ }^{1}{ }^{5}$ there is disproportionately limited data about mental health and its related factors from these countries. Within LMIC, further disparities exist such that regions with a relatively greater burden of common mental disorders (CMD) remain understudied. 
The majority of mental health studies in India are conducted in the progressive states of Goa and Kerala, which have high levels of female empowerment and education, important predictors of mental health. ${ }^{6-8}$ In contrast, reproductive-aged women from the state of Gujarat are three times less likely to have 10 or more years of education compared with those from Goa and Kerala and roughly four times more likely to be married before 18 years of age. ${ }^{9}$ Nevertheless, mental health in Gujarat is comparatively understudied, and there are reports of tremendous stigma against mental disorders among community members as well as healthcare providers, which further limits access to mental healthcare. ${ }^{10-13}$ Since healthcare priorities are often dictated by disease burden and its impact on individuals and their communities, information about CMD and its associated healthcare outcomes is necessary to guide prioritisation of mental health programmes.

The goal of this study was to determine the prevalence of CMD symptoms and characterise its association with three inter-related health factors, that is, (1) selfreported health status, (2) portion of yearly household income spent on healthcare and (3) healthcare usage in the previous year among an understudied population of women from rural western India based on a representative, cross-sectional survey.

\section{METHODS}

\section{Setting and study design}

Data were collected through a cross-sectional survey among women living in rural settings in the Anand district of Gujarat, India. Trained interviewers conducted face-to-face surveys in Gujarati, the local language. Participants were recruited in a quasi-randomised manner from two different settings: (1) Shree Krishna Hospital, a tertiary care centre serving the local rural population; and (2) 16 villages within a $20 \mathrm{~km}$ radius of the hospital. In the hospital clinic waiting areas, interviewers approached every third woman seated in the outpatient waiting area. Interviews were conducted in the waiting area but away from participants' family members and other patients in the clinic. Prior to recruitment in the villages, the layout of each village was obtained. Every third household in each of the village's colonies was approached and the first female who encountered the interviewer was asked to participate in the study. Community interviews were conducted at participants' residences. In both settings, two research supervisors, a male and a female, ensured privacy of all participants.

\section{Participants}

Seven hundred eligible women between the ages of 18 and 45 years who could comprehend and speak Gujarati and had a rural residence within the Anand district consented and participated in the study. For the purpose of this study, we excluded participants who were hospitalised or visiting inpatient relatives because they might experience acute emotional distress and have unique life circumstances that are different from participants identified in the outpatient area or in the community. A study of this nature with more than 642 participants would have a priori power of $90 \%$ ( $\alpha$ error $=0.01$ ) to detect a difference in proportions of $50 \%$ vs $35 \%$ for two groups. Based on our understanding before we conducted the study, these proportions would be reasonable to postulate for women with and without CMD who spend a substantial part of their income on health.

\section{Ethics}

Consent of the participants was obtained by trained interviewers prior to survey. Interviewers read the consent to participants in Gujarati and shared a singlepage fact sheet about the study with them. Willing participants were asked to sign or initial a separate consent form that was never linked to the survey to preserve the anonymous nature of the survey. Boston University Institutional Review Board and the Human Research Ethics Committee of HM Patel Center for Medical Care and Education reviewed the study independently and approved it.

\section{Data sources}

The data used in the study were collected as part of a broader survey comprised of five modules: (1) health status, (2) current and previous medical history, (3) lifestyle choices, (4) healthcare-seeking behaviour and (5) affordability of healthcare. The survey was drafted in English and underwent two iterations of translation back and forth between Gujarati and English. Five trained female interviewers piloted the survey with one volunteer each and then conducted all interviews from 1 October to 13 October 2011 . An average survey lasted $20-30 \mathrm{~min}$. The following variables were extracted for this study:

Exposure: CMD symptoms were assessed using the WHO Self-Reporting Questionnaire (SRQ-20). ${ }^{14}$ Owing to the absence of validation studies for SRQ-20 use in Gujarati population, we used the threshold for a positive test from a previous study conducted in a nearby location. Participants who responded 'yes' to eight or more questions were considered to have screened positive for CMD symptoms. ${ }^{15}$ SRQ-20 demonstrated excellent internal reliability in our population as measured by the Kuder Richardson 20 score of 0.90 .

\section{Outcomes:}

1. Health status was assessed by using the first question from the Short Form (SF)-12 instrument: 'In general, would you say your health is' with possible choices of (1) excellent, (2) very good, (3) good, (4) fair or (5) poor.

2. Expenditure of household income on healthcare was measured by asking participants, 'What most closely estimates the portion of your yearly household income spent on healthcare?' with choices offered as (1) none, (2) $<1 / 4$, , (3) $1 / 4$ to $<1 / 2$, (4) $1 / 2$ to $3 / 4$ or $(5)$ more than $3 / 4$. 
3. Number of healthcare visits in the previous year was determined by participant self-report. Participants were asked to report the number of times they visited a village, public, private, ayurvedic or homeopathic clinic/hospital in the previous year.

Confounders: Potential associations between CMD symptoms and healthcare usage, self-reported health status and expenditure on healthcare can be confounded by the presence of other diseases, age, marital status, income, education level and reproductive factors (total number of pregnancies, number of living children). Therefore, these factors were adjusted for using multivariable methods. Disease burden was based on selfreport of current conditions or past diagnoses of chronic diseases excluding any mental health disorders (see footnotes in table 1 for more details). Disease burden was estimated as an aggregate grouped into four categories: no disease, one disease, two diseases and three or more diseases. Marital status, education level and reproductive history were based on self-report. As described elsewhere, ${ }^{16}$ monthly household income was transformed into income/person/day values to account for variation in the household size. Daily per capita income was subsequently converted to US dollars using the average currency exchange rate from 2011, the year the study was conducted and categorised into three levels $(<\$ 0.25, \$ 0.25-\$ 1.25,>\$ 1.25)$.

All items, with the exception of SRQ-20 and SF-12, were study-specific and developed based on input from care providers and community members of these settings.

\section{Data management and analyses}

The paper-form surveys were entered into a database using Epi-Info software. All data entry was verified for errors by a team member different than the one performing the original data entry.

Descriptive data analyses were performed to assess the distribution of potential confounders with respect to CMD symptom screening status. Frequencies and percentages were calculated for categorical variables; associations with CMD symptom screening status were assessed using $\chi^{2}$ test for independence of attributes or Fischer's exact test. Bivariate associations of CMD symptom screening status with number of visits to clinic in the previous year, total number of pregnancies and number of live births were assessed using a one-way analysis of variance test. Ordered logistic regression analyses were used to quantify the relationship of positive CMD symptom screen with health status and household income spent on healthcare. The association of positive CMD screen and number of healthcare visits in the previous year was evaluated using negative binomial regression modelling. Unadjusted and adjusted incidence rate ratios (IRR) were calculated and interpreted as a count multiplier for the number of healthcare visits in the previous year. All three models adjusted for number of comorbid conditions, age, income, education, marital
Table 1 Sociodemographic and health characteristics of 658 reproductive-aged women from rural India stratified by screening status for CMD symptoms

\begin{tabular}{|c|c|c|c|c|}
\hline & \multirow{2}{*}{$\begin{array}{l}\text { Total } \\
\mathbf{N}\end{array}$} & \multicolumn{2}{|c|}{$\begin{array}{l}\text { CMD symptoms } \\
\text { (col \%) }\end{array}$} & \multirow[b]{2}{*}{ p Value } \\
\hline & & Positive & Negative & \\
\hline Participants (N) & 658 & 155 & 503 & \\
\hline Location: clinic & 311 & 43.9 & 48.3 & 0.33 \\
\hline $\begin{array}{l}\text { Clinic visits*, } † \\
(\text { mean(SD)) }\end{array}$ & $3.6(2.8)$ & $3.2(2.5)$ & $4.6(3.5)$ & $0.001 \dagger$ \\
\hline \multicolumn{5}{|l|}{ Health status } \\
\hline Excellent & 166 & 1.3 & 32.6 & $<0.001 \ddagger$ \\
\hline Very good & 95 & 3.9 & 17.7 & \\
\hline Good & 249 & 34.8 & 38.8 & \\
\hline Fair/poor & 148 & 60.0 & 10.9 & \\
\hline $\begin{array}{l}\text { HHI spent on } \\
\text { healthcare§ }\end{array}$ & \multicolumn{4}{|c|}{1 missing } \\
\hline$<1 / 4$ & 403 & 36.8 & 68.9 & $<0.001$ \\
\hline $1 / 4$ to $1 / 2$ & 184 & 38.0 & 24.9 & \\
\hline More than $1 / 2$ & 70 & 25.2 & 6.2 & \\
\hline \multicolumn{5}{|c|}{ Diseases or conditions $†, \emptyset$} \\
\hline Zero & 221 & 3.9 & 42.2 & $<0.001 \ddagger$ \\
\hline One & 155 & 17.4 & 25.8 & \\
\hline Two & 148 & 28.4 & 20.9 & \\
\hline Three or more & 134 & 50.3 & 11.1 & \\
\hline \multicolumn{5}{|l|}{ Current depression } \\
\hline Yes & 34 & 18.7 & 1.0 & NA \\
\hline Age (years) & \multicolumn{4}{|c|}{2 missing } \\
\hline $18-25$ & 226 & 28.6 & 36.3 & 0.18 \\
\hline $26-35$ & 249 & 39.6 & 37.5 & \\
\hline $36-45$ & 181 & 31.8 & 26.3 & \\
\hline Education & \multicolumn{4}{|l|}{2 missing } \\
\hline$<7$ th grade & 162 & 34.8 & 21.6 & $<0.001$ \\
\hline 7th-12th grade & 356 & 55.5 & 53.9 & \\
\hline$>12$ th grade & 138 & 9.7 & 24.5 & \\
\hline Marital status & \multicolumn{4}{|c|}{1 missing } \\
\hline Single & 97 & 8.4 & 16.7 & $0.03 \ddagger$ \\
\hline Married & 541 & 88.3 & 80.5 & \\
\hline $\begin{array}{l}\text { Divorced or } \\
\text { widowed }\end{array}$ & 19 & 3.3 & 2.8 & \\
\hline $\begin{array}{l}\text { Daily income per } \\
\text { person }\end{array}$ & \multicolumn{4}{|c|}{22 missing } \\
\hline$<\$ 0.25$ & 49 & 13.5 & 5.9 & 0.01 \\
\hline$\$ 0.25-\$ 1.25$ & 369 & 56.1 & 58.6 & \\
\hline$>\$ 1.25$ & 218 & 30.4 & 35.5 & \\
\hline $\begin{array}{l}\text { Pregnancies } \\
(\text { mean(SD) } \dagger\end{array}$ & $\begin{array}{l}2.13 \\
(1.78)\end{array}$ & $\begin{array}{l}2.55 \\
(1.92)\end{array}$ & $\begin{array}{l}2.00 \\
(1.71)\end{array}$ & $<0.001 \dagger$ \\
\hline $\begin{array}{l}\text { Living children } \\
(\text { mean(SD))† }\end{array}$ & $\begin{array}{l}1.60 \\
(1.35) \\
\end{array}$ & $\begin{array}{l}1.85 \\
(1.34) \\
\end{array}$ & $\begin{array}{l}1.52 \\
(1.34) \\
\end{array}$ & $0.001 \dagger$ \\
\hline \multicolumn{5}{|c|}{$\begin{array}{l}\text { *Number of clinic visits in the previous year based on self-report. } \\
\text { †ANOVA. } \\
\text { fFischer's exact test. } \\
\text { §Portion of yearly household income spent on healthcare } \\
\text { expenditure. } \\
\text { IParticipants were asked to identify using a list of } 33 \text { non-psychiatric } \\
\text { conditions and diseases. Twenty-two conditions and diseases } \\
\text { reported at least once by any participant; these were reviewed by } \\
\text { trained clinicians to identify chronic conditions. Based on the review, } \\
\text { an aggregate variable to represent chronic disease burden was } \\
\text { generated; it comprised of cardiovascular problems (coronary heart } \\
\text { disease, hypertension, positive history of heart attack or related } \\
\text { condition), pulmonary problems (difficulty breathing, chronic } \\
\text { allergies, asthma or chronic bronchitis), musculoskeletal pain } \\
\text { (chronic back problems, arthritis, difficulty opening mouth or limited } \\
\text { mobility due to pain), toothaches, anaemia and diabetes. } \\
\text { ANOVA, analysis of variance; CMD; common mental disorders. }\end{array}$} \\
\hline
\end{tabular}


status and reproductive history. Subgroup analyses to investigate differences between the hospital and community-based sample and sensitivity analyses to examine changes in the findings based on varying thresholds (6+ to 12+) for determining whether participants had positive CMD symptoms screen were performed to check for potential sources of biases. Multiple imputation using chained equations (5 imputations, 25 burn-in iterations) was performed to impute missing values for missing covariates; the one instance of a missing outcome was not imputed. The adequacy of burn-in period was assessed by examining stationarity of each chain by the end of burn-in periods from 1 to 30 . All statistical analyses were performed in STATA V.13.

\section{RESULTS}

Of the 700 participants interviewed for the study, 19 surveys were excluded due to incompleteness, 18 participants were excluded because they were visiting hospitalised relatives, and 5 surveys were classified as outliers due to their healthcare behaviour (these participants were identified using univariate distribution of healthcare visits because they had more than 20 clinical visits in the previous year due to serious health conditions) yielding an analytic sample of 658 women. Using the SRQ-20 to assess symptoms suggestive of CMD, 155 (22.8\%) participants screened positive having answered yes to at least 8 of 20 questions (table 1). Only 12 participants reported seeing a non-allopathic medical provider, and among them, all but 4 also saw an allopathic provider. Therefore, the number of healthcare visits was based on aggregate visits reported, regardless of the provider. On average, participants reported visiting a healthcare provider more than three times in the previous year. Few participants $(\mathrm{n}=14,2.13 \%)$ reported poor health status; therefore, we grouped participants who self-reported fair or poor health status into one category. The majority of the respondents considered their health status less than very good (ie, good or fair/poor). Over $60 \%$ of participants reported spending less than a quarter of their yearly income on healthcare; 6 participants $(0.9 \%)$ reported spending none, and $17(2.6 \%)$ reported spending more than $3 / 4$ of their yearly income, and thus responses were categorised into two groups (ie, spending $<1 / 4$ and more than $1 / 2$ of yearly income). Increased levels of education and household income were associated with decreased likelihood of screening positive for CMD symptoms.

More than four out of every five $(81.3 \%)$ respondents who screened positive for CMD symptoms reported they had not been diagnosed with depression or another mental health disorder by their healthcare provider, even though all but four of these women reported visiting a healthcare provider at least once in the past year (results not shown).

After controlling for confounders, screening positive for CMD symptoms was associated with more than a ninefold increase in the cumulative odds of reporting a worse health status (cumulative OR $($ cumOR $)=9.34 ; 95 \%$ CI 5.93 to 14.70 ) and a twofold increase in the cumulative odds of reporting a higher category of income expenditure on healthcare (cumOR $=2.25 ; 95 \%$ CL 1.48 to 3.44 ; table 2). Increasing number of comorbid nonpsychiatric conditions were associated with self-report of lower health status and greater portion of income spent on healthcare (see online supplementary table S1). In comparison to participants with no comorbid nonpsychiatric conditions, participants who reported three or more had more than twice the cumulative odds of reporting a poorer health status (cumOR $=2.61 ; 95 \%$ CL 1.60 to 4.24$)$ and more than three times greater cumulative odds of spending a higher portion of their yearly income on healthcare ( $\mathrm{OR}=3.46$; 95\% CL 2.05 to 5.84). Violations of the parallel regression assumptions for ordered logistic regression were ruled out using Brant test for health status $\left(\chi^{2}=29.76, \mathrm{df}=22 ; \mathrm{p}=0.67\right)$ and income spent on healthcare outcomes $\left(\chi^{2}=9.37, \mathrm{df}=22\right.$; $\mathrm{p}=0.67$ ).

Results from negative binomial regression models are reported in table 3. A negative binomial model was selected over Poisson to account for the overdispersion in the outcome $\left(\alpha=0.23 ; \chi^{2}=150.05, \mathrm{p}<0.001\right)$; improvement of model fit using zero inflated negative binomial regression was tested and ruled out using Vuong Test $(\mathrm{z}=0.42$, $\mathrm{p}=0.34$ ). Before adjusting for confounding, screening positive for CMD symptoms was associated with a $40 \%$ increase in the number of clinical visits in the previous year (IRR $=1.41 ; 95 \%$ CI 1.24 to 1.60 ). After adjusting for potential confounders, the association was attenuated but remained statistically significant (IRR $=1.22 ; 95 \%$ CI 1.05 to 1.42). Adjusted analyses revealed that in comparison to participants with no comorbidities, women who reported experiencing multiple non-psychiatric comorbidities were more likely to have greater number of clinic visits in the previous year (two diseases: IRR=1.18 (1.00 to 1.39 ); three

Table 2 Ordinal logistic regression models for the association between CMD symptoms and (a) self-reported health status and (b) yearly income spent on healthcare

$\begin{array}{ll}\begin{array}{l}\text { Self-reported } \\ \text { health status }^{a}\end{array} & \begin{array}{l}\text { Yearly income } \\ \text { spent on } \\ (n=633)\end{array} \\ \begin{array}{l}\text { healthcare } \\ (n=632)\end{array} \\ \text { CumOR (95\% CL)* } & \text { CumOR (95\% CL)* }\end{array}$

CMD symptoms: negative (ref)

Positive $\quad 9.34$ (5.93 to 14.70) 2.25 (1.48 to 3.44$)$
(SRQ-20 $\geq 8)$

Ordered categories: a=excellent, very good, good, fair/poor; $\mathrm{b}=<\frac{1}{4}, 1 / 4$ to $1 / 2,>1 / 2$.

${ }^{*}$ CumOR: cumulative OR adjusted for non-psychiatric comorbidities, age, income, education, marital status, total number of pregnancies and number of living children.

CMD, common mental disorders; SRQ-20, Self-Reporting

Questionnaire-20. 
Table 3 Multivariable negative binomial regression model estimates of count multiplier (IRR*) for clinical visits in the previous year based on screening status for CMD symptoms

\begin{tabular}{|c|c|}
\hline $\begin{array}{l}\text { Unadjusted } \\
\text { IRR (95\% CL) }\end{array}$ & $\begin{array}{l}\begin{array}{l}\text { Adjusted* } \\
(n=633)\end{array} \\
\text { IRR }(95 \% \mathrm{CL})\end{array}$ \\
\hline \multicolumn{2}{|l|}{ CMD symptoms: negative (ref) } \\
\hline $\begin{array}{l}\text { Positive } \\
\text { (SRQ-20 } \geq 8)\end{array}$ & $1.22(1.05$ to 1.42$)$ \\
\hline \multicolumn{2}{|c|}{$\begin{array}{l}\text { "IRR=incidence rate ratio is calculated by exponentiating } \beta \\
\text { coefficients of count models. IRR can be interpreted as count } \\
\text { multipliers. For example, screening positive for CMD symptoms is } \\
\text { associated with a } 42 \% \text { increase in the number of clinical visits in } \\
\text { the previous in comparison to those who do not screen positive } \\
\text { (unadjusted estimates). } \\
\text { †Adjusted for non-psychiatric comorbidities, age, income, } \\
\text { education, marital status, total number of pregnancies and number } \\
\text { of living children. } \\
\text { CMD, common mental disorders; SRQ-20, Self-Reporting } \\
\text { Questionnaire-20. }\end{array}$} \\
\hline
\end{tabular}

or more diseases: IRR=1.27 (1.06 to 1.52$)$; see online supplementary table S2).

Sensitivity analyses based on site of enrolment (clinic vs village), threshold values for positive screening for CMD symptoms and missing data did not reveal any changes in direction or statistical significance for the association of CMD symptoms with health status, percentage of income spent on healthcare expenditure or number of clinical visits in the previous year (table 4 ).

\section{DISCUSSION}

In this sample of reproductive-aged women from rural western India, approximately one out of every four participants screened positive for CMD symptoms. High mental distress in this population may be attributed to overall circumstances of women's lives in this setting. We have previously reported that CMD symptoms in this setting are closely associated with poor socioeconomic status, food insecurity and exposure to traumatic events. ${ }^{17}$ Despite visiting a healthcare provider at least once in the previous year, the majority of participants reported that they had not been diagnosed with depression or other mental health disorder by their healthcare provider. Screening positive for CMD symptoms was associated with worse self-reported health status, a higher portion of household income expended on healthcare, and an increased number of healthcare visits. The associations found in our study were robust to subgroup, sensitivity and missing data analysis with the exception of a stronger association between health status and CMD symptoms among women interviewed in clinic compared with those interviewed in the village.

Our finding of potentially unrecognised CMD (81.3\%) is similar to the $79.0 \%$ depression prevalence reported by Kohli $e t a l^{18}$ for primary care attendees from another rural region in India. The high rates are likely to be driven by two main factors. First, compared with western societies, people in India are more likely to attribute mental illness to personally controllable factors, and thus mental health in rural India is associated with a tremendous amount of stigma and social disadvantage. ${ }^{10} 19$ Consequently, Indians may be less willing to disclose psychological symptoms. Indeed, studies have shown that most Indian patients suffering from mental disease present with somatic symptoms, which may increase the likelihood that CMD goes undetected. ${ }^{20-23}$ Second, there is a scarcity of mental healthcare providers in India, and other healthcare providers do not receive adequate mental health training. ${ }^{24}$ Thus, in primary care settings, mental illness may not be considered in the differential diagnoses, especially in the context of an atypical presentation, leading to inadequate identification of mental diseases. ${ }^{25}$

Our findings suggest that women screening positive for CMD symptoms had visited their providers more frequently and were more likely to spend a larger portion of their household income on healthcare. The association between CMD symptoms and healthcare cost also could be self-perpetuating. Women screening positive

Table 4 Results of subgroup analyses by location of survey, sensitivity analyses using stricter threshold value for positive screening for CMD symptoms, and imputed data set to account for missing values

\begin{tabular}{|c|c|c|c|}
\hline & 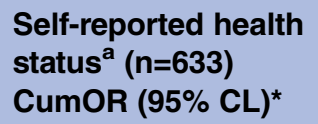 & $\begin{array}{l}\text { Yearly income spent } \\
\text { on healthcare }{ }^{b}(n=632) \\
\text { CumOR }(95 \% \text { CL) }\end{array}$ & $\begin{array}{l}\text { Number of clinical visits } \\
\text { in previous year }(n=633) \\
\text { IRR }(95 \% \text { CL) }\end{array}$ \\
\hline Original & 9.34 (5.93 to 14.70$)$ & 2.25 (1.48 to 3.44$)$ & 1.22 (1.05 to 1.42$)$ \\
\hline \multicolumn{4}{|l|}{ By location } \\
\hline Clinic & 11.79 (5.94 to 23.40$)$ & 2.77 (1.46 to 5.24$)$ & $1.21(0.98$ to 1.51$)$ \\
\hline Village & $7.72(4.14$ to 14.37$)$ & 2.04 (1.14 to 3.65$)$ & 1.25 (1.03 to 1.52$)$ \\
\hline \multicolumn{4}{|l|}{ Threshold value } \\
\hline$S R Q-20 \geq 12$ & $6.82(3.72$ to 12.51$)$ & 3.37 (1.98 to 5.75$)$ & $1.37(1.14$ to 1.64$)$ \\
\hline \multicolumn{4}{|l|}{ Missing data } \\
\hline Imputed data set & $8.42(5.44$ to 13.05$)$ & 2.23 (1.48 to 3.36$)$ & $1.23(1.06$ to 1.42$)$ \\
\hline
\end{tabular}


have considerably lower appraisal of their personal health than those who screen negative, which probably explained their seeking healthcare more often. Indian women who are suffering from mental illness are known to present to primary clinics with somatic rather than psychological symptoms, which may lead to underdiagnosis and treatment of their CMD. ${ }^{23}$ Patients and their medical providers may continue to search for a physical cause, incurring healthcare costs and a greater number of healthcare visits, while the underlying mental illness remains unrecognised and unaddressed. ${ }^{25} 26$

Alternatively, it is also possible that providers may have suspected mental illness but not directly addressed it with the patient; providers may have attributed possible mental illnesses to female suppression and poverty. In such instances, providers may find themselves illpositioned to assist with underlying risk factors for mental health problems. Given the study design and the data collected, it is impossible to rule out this scenario; nevertheless, it is striking that the majority of women screening positive for CMD symptoms report they never received a diagnosis from a healthcare provider despite having reported seeing a provider at least once in the previous year. This represents a missed opportunity to screen and assess women for CMD. Identification of women who may have CMD or be at risk of developing CMD could facilitate detection, assessment and treatment.

The high prevalence of poverty in India creates important barriers for recognition and treatment of CMD. Owing to healthcare-related costs, 63 million people in India fall below the poverty line every year. ${ }^{27}$ This number is expected to rise given the inevitable increase in the prevalence of chronic, noncommunicable diseases in India, which carry a greater financial burden than communicable diseases. ${ }^{28} 29$ Treating CMD with pharmacological and psychological therapies has been shown to reduce the economic burden of healthcare among adults. ${ }^{30} 31$ Thus, treatment of mental illness could break this vicious cycle of poverty and CMD. ${ }^{30}{ }^{31}$ The Indian government recently proposed to revamp its mental health services through the National Mental Health Policy of India (NMHPI). NMHPI proposes to increase the number of mental healthcare providers and expand coverage from 182 to 648 districts and support 11 centres of excellence in mental health to train the next generation's mental healthcare providers. $^{32}$ Despite the laudable NMHPI proposal, the urgent needs of rural Indian women may continue to go unaddressed because the proposal may be difficult to implement due to lack of funding and a cohesive implementation plan. ${ }^{33}$

Integration of mental healthcare into primary care could provide a solution because women suffering from mental illness most often present to primary care settings. ${ }^{34} 35$ The increased frequency of healthcare visits among women screening positive for CMD symptoms in our study potentially highlights missed opportunity for intervention. Depression screening needs to be carried out in conjunction with a systematic approach to ensuring adequate access to mental health assessment and care. ${ }^{36}$ It is well established that integrated care models, such as collaborative care, effectively integrate depression and primary care, can improve clinical outcomes, and can also be carried out by non-specialist health workers. ${ }^{37} 38$ Such approaches have also been tested in India; Patel et $a l^{39}$ tested a collaborative stepped care (CSC) model that included four levels of referral before a clinical specialist became involved in care. The CSC model begins with CMD screening for adult patients that present to clinic with a village health worker, and progresses through therapeutic steps of increasing intensity including yoga, behavioural and pharmacological interventions. Patients who do not respond to a less intense treatment are stepped up to a higher intensity therapeutic option. The CSC model improves mental illness over a 6-month period and holds promise as an effective mechanism to improve mental health in rural India. ${ }^{40}$ However, the wide implementation of the CSC model in India is lacking and has been limited to Goa and South India, two regions in India that face a comparatively lower burden of mental diseases. ${ }^{41} 42$ Thus, there is a need for cost-effective treatment plans that leverage primary care providers and staff already working in the primary care setting.

The findings from our study must be interpreted in the context of its limitations. We identified CMD symptoms using a validated screening questionnaire (SRQ-20) instead of a diagnostic structured clinical interview. It is possible that women who screen positive for CMD symptoms may have had subsyndromal symptoms. However, our decision to use SRQ-20 for this study was based on sound principles: (1) the SRQ-20 was developed specifically for use in global health research conducted in low-resource setting. It is validated, well accepted and has been described as a cost-effective way of measuring mental health; ${ }^{15}$ (2) The purpose of this study was not to investigate psychiatric practice or clinical management of CMD in India but rather to understand the characteristics of women who might be suffering from mental illness; and (3) In the context of India, where mental health literacy is limited, administration of a high face validity instrument such as SRQ-20 with yes and no responses lowers the interview burden on participants. ${ }^{14}$ Our data were collected through a cross-sectional survey, and thus we cannot comment on the causal relationship of our findings; it is possible that women with poor appraisal of their personal health develop CMD symptoms. Presence of comorbidities among our participants was captured through self-report and therefore is vulnerable to differential recall where women with positive screen for CMD symptoms potentially over-report their conditions. However, such misclassification would likely bias our estimates towards the null hypotheses. Our estimates of household expenditure on healthcare were based on a single question and 
had broad categories and therefore may lack precision. However, we used trained local interviewers to pilot the question. Moreover, in the context of rural Gujarat, this instrument provides information about healthcare costs that is difficult to capture and not available in other databases. ${ }^{35}$ Finally, our finding of increased cumulative odds of reporting a higher portion of household expenditure on healthcare with increasing number of comorbidities suggests that our instrument performed as expected.

In conclusion, we found a high number of Indian women screening positive for CMD symptoms that were unrecognised and associated with adverse impacts on overall health and economic well-being. Our findings suggest that there is a need to screen, assess and manage CMD in primary healthcare and communitybased settings in India. This could, in turn, improve overall health status and reduce healthcare-related economic burden.

Twitter Follow Somashekhar Nimbalkar at @somu_somu

Contributors AS, NF, AP and SN conceptualised, designed and implemented the study in India. AS carried out the initial analyses, drafted the initial manuscript and approved the final manuscript as submitted. NF, NB, AP, TAMS, JV, JA, AP, EO and SN provided input to the analyses, contributed to the drafting of the manuscript and approved the final manuscript as submitted. EO conceptualised and designed the study.

Funding This study was supported by Boston University Dudley Allen Sargent Research Grant. Contribution by coauthors was partially supported by TL1-TR001454 (to AS) and KL2TR000160 (to NB) from National Center for Advancing Translational Sciences, P60-MD006912-05 (to JA) from National Institute on Minority Health and Disparities, and Joy McCann Endowment (to TAMS).

Disclaimer The content is solely the responsibility of the authors and does not necessarily represent the official views of the NIH.

Competing interests None declared.

Patient consent Obtained.

Ethics approval IRB at Boston University; Ethics Committee at Pramukhswami Medical College.

Provenance and peer review Not commissioned; externally peer reviewed.

Data sharing statement No additional data are available.

Open Access This is an Open Access article distributed in accordance with the Creative Commons Attribution Non Commercial (CC BY-NC 4.0) license, which permits others to distribute, remix, adapt, build upon this work noncommercially, and license their derivative works on different terms, provided the original work is properly cited and the use is non-commercial. See: http:// creativecommons.org/licenses/by-nc/4.0/

\section{REFERENCES}

1. Whiteford HA, Degenhardt L, Rehm J, et al. Global burden of disease attributable to mental and substance use disorders: findings from the Global Burden of Disease Study 2010. Lancet 2013;382:1575-86.

2. Murray CJL, Lopez A, eds. The global burden of disease: a comprehensive assessment of mortality and disability from disease, injures and risk factors in 1990 and projected to 2020. Cambridge, MA: Harvard University Press on behalf of the World Health Organization and the World Bank, 1996:1-51.

3. Druss BG, Walker ER. Mental disorders and medical comorbidity. Synth Proj Res Synth Rep 2011:1-26. http://www.rwjf.org/en/library/ research/2011/02/mental-disorders-and-medical-comorbidity.html (accessed 10 Feb 2015).

4. Egede LE. Major depression in individuals with chronic medica disorders: prevalence, correlates and association with health resource utilization, lost productivity and functional disability. Gen Hosp Psychiatry 2007;29:409-16.

5. Chan M. Mental health and development: targeting people with mental health conditions as a vulnerable group. World Health Organization. 2010. http://www.who.int/mental_health/policy/ development/mh devel targeting_summary_2010 en.pdf (accessed 10 Feb 2015).

6. Ganguli HC. Epidemiological findings on prevalence of mental disorders in India. Indian J Psychiatry 2000;42:14-20.

7. Shidhaye R, Patel V. Association of socio-economic, gender and health factors with common mental disorders in women: a population-based study of 5703 married rural women in India. Int J Epidemiol 2010;39:1510-21.

8. Patel V, Lund C, Hatherill S, et al. Mental disorders: equity and social determinants. In: Blas E, Kurup AS, eds. Equity, social determinants and public health programmes. Geneva: World Health Organization, 2010:115-35.

9. Kishor S, Gupta K. Gender equality and women's empowerment in India. Mumbai, 2009. http://rchiips.org/nfhs/a_subject_report_ gender_for_website.pdf

10. Liu MC, Tirth S, Appasani R, et al. Knowledge and attitudes toward depression among community members in rural Gujarat, India. $J$ Nerv Ment Dis 2014;202:813-21.

11. Amin G, Shah S, Vankar GK. The prevalence and recognition of depression in primary care. Indian J Psychiatry 1998;40:364-9.

12. Saddichha S, Vibha P, Saxena MK, et al. Behavioral emergencies in India: a population based epidemiological study. Soc Psychiatry Psychiatr Epidemiol 2010;45:589-93.

13. Almanzar S, Shah N, Vithalani S, et al. Knowledge of and attitudes toward clinical depression among health providers in Gujarat, India. Ann Glob Health 2014;80:89-95.

14. World Health Organization. A user's guide to the self reporting questionnaire. Geneva: World Heal Organ, 1994.

15. Harpham T, Reichenheim M, Oser R, et al. Measuring mental health in a cost-effective manner. Health Policy Plan 2003;18:344-9.

16. Soni A, Fahey N, Phatak AG, et al. Differential in healthcare seeking behavior of mothers for themselves versus their children in rural India: results of a cross sectional survey. Int Public Healh J 2014:6:57-66.

17. Fahey N, Soni A, Allison J, et al. Higher levels of education mitigate the relationship between perceived stress and positive screening for common mental disorders among women in rural India: results of a cross-sectional study. Ann Glob Health 2016; In Press.

18. Kohli C, Kishore J, Agarwal P, et al. Prevalence of unrecognised depression among outpatient department attendees of a rural hospital in Delhi, India. J Clin Diagn Res 2013;7:1921-5.

19. Nieuwsma JA, Pepper CM, Maack DJ, et al. Indigenous perspectives on depression in rural regions of India and the United States. Transcult Psychiatry 2011;48:539-68.

20. Pereira B, Andrew G, Pednekar S, et al. The explanatory models of depression in low income countries: listening to women in India. $J$ Affect Disord 2007;102:209-18.

21. Andrew G, Cohen A, Salgaonkar S, et al. The explanatory models of depression and anxiety in primary care: a qualitative study from India. BMC Res Notes 2012;5:499.

22. Nambi SK, Prasad J, Singh D, et al. Explanatory models and common mental disorders among patients with unexplained somatic symptoms attending a primary care facility in Tamil Nadu. Natl Med $J$ India 2002;15:331-5.

23. Grover S, Dutt A, Avasthi A. An overview of Indian research in depression. Indian J Psychiatry 2010;52:S178-88.

24. WHO-AIMS report on Mental Health System in Gujarat, India. 2006. https://www.mindbank.info/item/4531 (accessed 31 May 2015).

25. Paykel ES, Priest RG. Recognition and management of depression in general practice: consensus statement. BMJ 1992;305:1198-202.

26. Linden $\mathrm{M}$, Lecrubier $\mathrm{Y}$, Bellantuono $\mathrm{C}$, et al. The prescribing of psychotropic drugs by primary care physicians: an international collaborative study. J Clin Psychopharmacol 1999;19:132-40.

27. National Health Policy 2015: Ministry of Health and Family Welfare. http://www.mohfw.nic.in/showfile.php?lid=3014 (accessed 22 Oct 2015).

28. Berman P, Ahuja R, Bhandari L. The impoverishing effect of healthcare payments in India: new methodology and findings. Econ Polit Wkly 2010;xlv:65-71.

29. Binnendijk E, Koren R, Dror DM. Can the rural poor in India afford to treat non-communicable diseases. Trop Med Int Health 2012;17:1376-85. 
30. Patel V, Weobong B, Nadkarni A, et al. The effectiveness and cost-effectiveness of lay counsellor-delivered psychological treatments for harmful and dependent drinking and moderate to severe depression in primary care in India: PREMIUM study protocol for randomized controlled trials. Trials 2014;15:101.

31. Patel V, Chisholm D, Rabe-Hesketh S, et al. Efficacy and cost-effectiveness of drug and psychological treatments for common mental disorders in general health care in Goa, India: a randomised, controlled trial. Lancet 2003;361:33-9.

32. Sinha SK, Kaur J. National mental health programme: manpower development scheme of eleventh five-year plan. Indian J Psychiatry 2011;53:261.

33. Sharma DC. India's new policy aims to close gaps in mental health care. Lancet 2014;384:1564

34. Das J, Do Q-T, Friedman J, et al. Mental health patterns and consequences: results from survey data in five developing countries. World Bank Econ Rev 2008;23:31-55.

35. Patel V, Chisholm D, Kirkwood BR, et al. Prioritizing health problems in women in developing countries: comparing the financia burden of reproductive tract infections, anaemia and depressive disorders in a community survey in India. Trop Med Int Health 2007;12:130-9.

36. Kagee A, Tsai AC, Lund C, et al. Screening for common mental disorders in low resource settings: reasons for caution and a way forward. Int Health 2013;5:11-14.
37. Woltmann E, Grogan-Kaylor A, Perron B, et al. Comparative effectiveness of collaborative chronic care models for mental health conditions across primary, specialty, and behavioral health care settings: systematic review and meta-analysis. Am J Psychiatry 2012;169:790-804.

38. van Ginneken N, Tharyan P, Lewin S, et al. Non-specialist health worker interventions for the care of mental, neurological and substance-abuse disorders in low- and middle-income countries. Cochrane Database Syst Rev 2013;(11):CD009149.

39. Patel VH, Kirkwood BR, Pednekar S, et al. Improving the outcomes of primary care attenders with common mental disorders in developing countries: a cluster randomized controlled trial of a collaborative stepped care intervention in Goa, India. Trials 2008;9:4.

40. Patel V, Weiss HA, Chowdhary N, et al. Effectiveness of an intervention led by lay health counsellors for depressive and anxiety disorders in primary care in Goa, India (MANAS): a cluster randomised controlled trial. Lancet 2010;376:2086-95.

41. Singla D, Lazarus A, Atif N, et al. 'Someone like us': delivering maternal mental health through peers in two South Asian contexts. $J$ Affect Disord 2014:168:452-8.

42. Patel V, Kirkwood BR, Pednekar S, et al. Gender disadvantage and reproductive health risk factors for common mental disorders in women: a community survey in India. Arch Gen Psychiatry 2006;63:404-13. 